\title{
A "NOVA" LEI DO EXERCÍCIO PROFISSIONAL DA ENFERMAGEM: UMA ANÁLISE CRIT́ICA
}

Jorge Lorenzetti*

No dia 8 de junho de 1987, o Presidente da República assinou o decreto $\mathrm{n}^{0}$ 94.406 (Anexo II), que regulamenta a Lei 7.498 (Anexo I), de 25 de junho de 1986, que dispõe sobre o exercício profissional da enfermagem.

Com isto, conclui-se a primeira etapa de um processo de quase 10 nos de luta pela atualização do exercício profissional (LEP) da enfermagem, estabelecida até aqui, na Lei no 2.604 de 17 de setembro de 1955 (anexo III).

Torna-se oportuno e indispensável uma análise crítica sobre este processo que atravessamos e um posicionamento oficial da ABEn sobre os encaminhamentos de aplicação dos pontos positivos da LEP e o tratamento a ser dado para as questões polêmicas, insuficientes e não contempladas.

A questão da legislação profissional e trabalhista da enfermagem precisa ser analisada no contexto da evolução e das dificuldades da profissão.

A legislação que disciplina as condições e o papel de uma profissão e do próprio conjunto da Sociedade, como a constituição, é o resultado da situação objetiva das relaçẽos sociais e não o dese jo ideal de um grupo ou de seus dirigentes. Ou seja, a Lei estabelece e disciplina situações dadas e não o contrário. É preciso primeiro conquistar e afirmar na prática uma determinada realidade para depois assegura-lá em lei. Não será a lei que vai trazer, por si só, pela chamada "força da lei", a conquista das nossas aspirações e reivindicações. Poderemos ter leis mais ou menos avançadas, porém, elas não substituem a nossa força concreta, resultado do nosso grau de organização, no contexto da sociedade. Este entendimento é fundamental para orientar a nossa análise e consideraçẽos sobre a legislação de enfermagem.

Hoje, a enfermagem brasileira ainda não possui uma só linha de legislação que proteja o seu trabalho, mesmo sendo amplamente considerada uma profissão com características especiais. A única Lei, neste sentido, que conseguimos aprovação no Congresso Nacional, de jornada de 30 horas para todo o pessoal de enfermagem e com algumas conquistas de condições de trabalho, foi simplesmente vetada, em 1983, pelo Presidente da República com a humilhante justificativa de que não havia razões sociais e profissionais para sua aprovação.

Faz-se necessário recuperar a história da luta por uma legislação de enfermagem, que atenda aos nossos interesses e através de um amplo e profundo debate, entender e explicar as razões e motivos que são o pano de fundo desta situação.

A criação do Conselho Federal de Enfermagem, COFEn, e dos Conselhos Regionais de Enfermagem, COREns, através da Lei n? 5.905 de 12 de julho de 1973 , estabelece a exigência de uma nova legislação do exercício profissional da enfermagem. A lei ABEn-Central, de 17 de setembro de 1955, que até aqui regulamentava o exercício da enfermagem, determinava que a fiscalização da profissão era responsabilidade do Serviço Nacional de Fiscalização da Medicina e Farmácia. Com isto, o COFEn, por sua iniciativa e sem debate no interior da enfermagem, elabora um Projeto de Lei que ef etivamente começa a tramitar no Congresso Nacional em 1980 e é aprovado, finalmente, em 1986. Desta forma, a discussão, para enfermagem brasileira, de uma nova lei do exercício profissional, ocorre durante a tramitação deste projeto no Congresso Nacional. E, nestes 6 anos de tramitação e debate até a sua aprovação, a enfermagem brasileira não conseguiu chegar a um consenso mais geral sobre uma Lei do Exercício Profissional que atendesse aos interesses do conjunto da profissão.

Consideramos fundamentalmente que este debate se aprof unde e se multiplique em todo o Brasil, não só como instrumento indispensável para garantir a aplicação dos pontos positivos desta "nova" lei, mas para alcançarmos na perspectiva da superação dos problemas que estão na raiz destas divergências. E, assim, implementarmos um crescimento da enfermagem que possibilite, no futuro, a conquista de uma legislação profissional ef etivamente nova e voltada para os interesses da profissão e das necessidades de saúde da população.

\footnotetext{
* Coordenador da Comissão de Legislação da Associação Brasileira de Enfermagem ABEn-Central.
} 
Por isso, com este texto, pretendemos apenas contribuir para o debate e estimular a realização de seminários e cursos de legislação em todo o país.

\section{ANÁlISE CRÍTICA DA "NOVA" LEI DO EXERCÍCIO PROFISSIONAL DA ENFERMAGEM}

$\mathrm{Na}$ primeira etapa de tramitação do projeto, 1980-1982, na Câmara dos Deputados, identificamos duas posições da enfermagem brasileira, mais precisamente, entre os enfermeiros, pois, em nenhum momento, tivemos um processo nacional de discussão que envolvesse o conjunto de enfermagem (enfermeiros, técnicos, auxiliares e atendentes). Mesmo considerando que se tratava de uma única Lei regulamentanto o exercício de profissionais diversos de uma categoria profissional, ou uma categoria profissional com diversas subcategorias, ou seja, a categoria profissional da enfermagem que contém as subcategorias dos enfermeiros, técnicos, auxiliares e atendentes.

A primeira posição que identificamos entre os enfermeiros, nesta primeira etapa, é a do grupo que simplesmente apóia a aprovação do projeto. Neste grupo está a COFEn, a ABEn- Central e a grande maioria dos COREns e ABEns.

A segunda posição, identificada no Congreso Brasileiro de Enfermagem de Mananus, de 1981, por proposta da ABEn-SC, é a do grupo que é contra a aprovação do projeto em tramitação e a favor da elaboração de um novo projeto, a partir de ampla discussão por toda a enfermagem do país, e contemplando os aspectos profissionais, trabalhistas e organizativos da enfermagem. Neste grupo estão algumas ABEns e Sindicatos de Enfermeiros.

Com a aprovação do projeto na Câmara dos Deputados em 1982, e o início da sua tramitação no Senado Federal, a situação se modifica, pois a posição de elaboração de um novo projeto fica inviabilizada. A divergência então, passa a ser apresentação ou não de emendas no senado.

Os Sindicatos dos Enfermeiros sustentam a posição de apresentação de emendas, que são efetivamente apresentadas e após negociação, o projeto é aprovado no Senado com emendas, exigindo à Câmara dos Deputados que aprecie e aprove o mesmo, de acordo com a versão final do Senado. Assim, o Congresso Nacional, em 05 de junho de 1986, aprova a nova lei e a encaminha ao Presidente da República para ser sancionada.

\section{Pontos positivos do projeto aprovado no Congresso Nacional}

- Participação da enfermagem no planejamento, execução e avaliação da programação de saúde e nos pla- nos assistenciais de saúde, incluída consulta de enfermagem.

- Necessidade de órgão de enfermagem na estrutura básica de todas as instituições de saúde, sob direção de enfermeiros.

- Obrigatoriedade de habilitação legal e registro no Conselho (COREns/COFEn) para exercício da enfermagem.

- Reconhecimento legal do técnico de enfermagem.

- Reconhecimento da nova autonomia técnica do enfermeiro para exercício da enfermagem nas instituições de saúde e para o exercício liberal da profissão.

- Obrigatoriedade de registro das instituições privadas de serviços de saúde e de ensino nos Conselhos de Enfermagem (COREns).

- Definição do prazo de dez anos para profissionalização de todo o pessoal de enfermagem (atendentes de enfermagem).

\section{Pontos negativos do projeto aprovado no Congresso Nacional}

- Não faz nenhuma referência aos parâmetros dos recursos humanos necessários para uma adequada assistência de enfermagem.

- Exclui completamente as condições de trabalho necessárias para o exercício de uma profissão com características especiais como a enfermagem.

- Não faz nenhuma referência ao direito de livre organização da enfermagem a partir do local de trabalho.

\section{Ponto polêmico do projeto aprovado no Congresso Nacional}

A definição das atribuições de cada um dos exercentes da enfermagem é um dos pontos mais importantes da problemática atual e que identificamos como polêmico, porque a versão final aprovada conta com enfermeiros que discordam e têm uma forte oposição e indignação aos auxiliares de enfermagem.

A versão original aprovada na Câmara dos Deputados tinha uma concepção mais genérica das atribuições, e assim, não despertava maiores dificuldades, porém, limitava as atividades na área de obstetrícia apenas à obstetriz ou enfermeira obstétrica.

As emendas apresentadas no Senado corrigiram esta deficiência na área da obstetrícia, porém, ao procurar especificar e detalhar as atribuições de cada profissional, introduziu conceitos e definições polêmicas e problemáticas.

A primeira é a que cabe ao enfermeiro:

- prevenção e controle sistemático da infecção hospitalar e de doenças transmissíveis em geral.

- prevenção e controle sistemático de danos que possam ser causados à clientela durante a assistência de enfermagem. 
- assistência de enfermagem a gestante, parturiente e puérpera.

- cuidados diretos de enfermagem a pacientes graves com risco de vida.

- cuidados de enfermagem de maior complexidade técnica e que exijam conhecimentos de base científica e capacidade de tomar decisões imediatas.

A segunda é que ao definir as competências do auxiliar de enfermagem estabelece as mesmas como sendo "de natureza repetitiva".

$\mathrm{Na}$ verdade, esta classificação e estruturação das competências reflete uma concepção estratificada, hierarquizada e autoritária da prática da enfermagem e a busca de uma "saída legal", para a crise da prática atual do enfermeiro. E isto, num momento histórico em que a enfermagem procura aprofundar todo um questionamento sobre as suas relações internas de trabalho, o objeto do seu trabalho e o papel do enfermeiro. Não pode ser este o caminho e a forma de enfrentarmos um problema central como este para a profissão hoje, pois, ao contrário, isto amplia obstáculos e dificuldades.

A Lei do Exercício Profissional deveria estabelecer parâmetros referenciais das competências, reafirmar o princípio da democratização interna do trabalho para uma adequada assistência de enfermagem e ter como preocupação central a garantia das condições externas e determinantes do pleno exercício profissional.

\section{Os vetos do presidente da República ao projeto aprovado no Congresso Nacional}

No dia 25 de junho de 1986, o presidente da República sanciona a "nova" LEP com 19 vetos ao projeto aprovado no Congresso Nacional (ver anexo).

Toda a orientação dos vetos é no sentido de impedir qualquer conquista externa mais ampla para a enfermagem, preservando, assim, os interesses da atual política de saúde, privatizante, hospitalar, curativa e empresarial. Por exemplo, a justificativa oficial para vetar 0 artigo 5: "a obrigatoriedade da inclusão de órgão de enfermagem da instituição de saúde seria desnecessariamente onerosa para pequenas unidades hospitalares". Para o artigo 10: "é discutível a autonomia na execução dos serviços e da assistência de enfermagem sem a supervisão médica".

Assim, os vetos mutilam os avanços significativos que teríamos na Lei como autonomia, mercado de trabalho, organização profissional e a profissionalização dos atendentes de enfermagem.

Os vetos presidenciais derrubam a metade dos pontos positivos listados anteriormente ao eliminar os ítens 2, 3, 6 e parcialmente o ítem 7 .

No tocante às garantias do papel da enfermagem no ensino, com os vetos, a "nova" LEP representa um retrocesso em relação à anterior. Porém, como a Lei no 2.604 não foi revogada, torna-se necessário usá-la para manter assegurado a nossa participação no ensino de enfermagem.

\section{$O$ decreto no 94.406 que regulamenta a "nova" lei do exercício profissional}

No Brasil uma lei aprovada pelo Congresso Nacional precisa ser sancionada pelo presidente da República, que pode vetar total ou parcialmente, e para entrar em vigor deve ter um decreto de regulamentação do poder executivo.

No dia 08 de junho de 1987 o presidente da República assinou o decreto regulamentando a Lei no 7.498 do exercício profissional da enfermagem.

Este decreto de regulamentação não faz mensão nenhuma ao ítem da profissionalização dos atendentes, exige a comprovação, apenas nas instituições públicas e se restringe, praticamente, somente na questão das atribuições dos exercentes de enfermagem. Nese aspecto, faz uma tentativa de corrigir o texto da lei ampliando o campo de atuação do técnico de enfermagem como assistente do enfermeiro e eliminando a "natureza repetitiva" das competências do auxiliar de enfermagem e detalhando suas atribuições numa visão mais ampla do que previa a lei.

0 conjunto do decreto, ignorando questões externas determinantes, confirma e completa as medidas do executivo de eliminar os avanços significativos do projeto original, demonstrando, mais uma vez, claramente, o compromisso do Governo com os interesses do setor privado hegemônico e dominante na política de saúde brasileira, com a conseqüente política de desvalorização da enfermagem e desinteresse pelas reais necessidades de saúde da população.

\section{CONCLUSÃO}

A atual diretoria ABEn considera importante e prioritária a luta pela aplicação dos pontos positivos da legislação do exercício profissional que agora entra em vigor. E reafirma a sua disposição de continuar implementando a luta pelas conquistas na prática das reivindicações históricas da enfermagem e a valorização da profissão.

Para tanto, atraveś da Comissão de Legislação e do conjunto da ABEn, em articulação com todas as entidades representativas da enfermagem, destaca as seguintes atividades neste processo:

- Implementação de um amplo debate em todo o Brasil sobre os diversos aspectos da LEP, as tarefas de sua aplicação e desafios para seu aperfeiçoamento. A Comissão de Legislação se dispõe a desenvolver cursos, seminários e debates em todas as Seções e Regionais, de preferência envolvendo toda a enfermagem e suas entidades. 
- Implementação de um plano nacional de carreira para enfermagem como instrumento do ef etivo reconhecimento legal do técnico de enfermagem e de valorização do conjunto da enfermagem.

- Desenvolvimento de um projeto nacional de profissionalização dos atendentes, recomendando ao COFEn o imediato processo de registro de enfermagem para debate e encaminhamento unitário de todas as questões de interesse geral da enfermagem brasileira.

Brasília, 09 de julho de 1987

Texto aprovado pela

Diretoria Central da ABEn, em reunião realizada em

Brasília, nos dias 9, 10 e 11/07/87

\section{ANEXO I \\ Texto da Lei $n$ ? 7498 (LEP)}

\section{Dispõe sobre a regulamentação do exercício da enfermagem e dá outras providências.}

0 presidente da República. Faço saber que o Congresso Nacional decreta e eu sanciono a seguinte Lei:

Art. 19 É livre o exercício da enfermagem em todo o território nacional, observadas as disposições desta Lei.

Art. 20. A enfermagem e suas atividades auxiliares somente podem ser exercidas por pessoas legalmente habilitadas e inscritas no Conselho Regional de Enfermagem com jurisdição na área onde ocorre o exercício.

Parágrafo único A enfermagem é exercida privativamente pelo Enfermeiro, pelo Técnico de Enfermagem, pelo Auxiliar de Enfermagem e pela Parteira, respeitados os respectivos graus de habilitação.

Art. 3. O planejamento e a programação das instituições e serviços de saúde incluem planejamento e programação de enfermagem.

Art. 4. A programação de enfermagem inclui a prescrição da assistência de enfermagem.

Art. 50. A estrutura básica da instituição de saúde pública ou privado, inclui, obrigatoriamente, órgãos de onfermagem que integrarão sua administração superior.

§ 10. A direção do órgão de enfermagem será exercida, sempre, por enfermeiro, incluído nas definições do art. $6^{0}$.

$\S 2$ : Comprovada a inexistência de profissional disponível...
Art. 6? São enfermeiros:

1) 0 titular do diploma de Enfermeiro conferido por instituição de ensino, nos termos da lei;

2) 0 titular do diploma ou certificado do Obstetriz ou de Enfermeira Obstétrica, conferido nos termos da Lei; 3) 0 titular do diploma ou certificado de Enfermeira e a titular do diploma ou certificado de Enfermeira Obstétrica ou Obstetriz, ou equivalente, conferido por escola estrangeira segundo leis do país, registrado em virtude de acordo de intercãmbio cultural ou revalidado no Brasil como diploma de Enfermeiro, de Enfermeira Obstétrica ou de Obstetriz;

4) Aqueles que, não abrangidos pelos incisos anteriores, obtiveram título de Enfermeiro conforme o disposto na alínea d do art. $3^{\circ}$ do Decreto $\mathrm{n}^{0}$. 50.387, de 28 de março de 1961.

Art. 7․ São Técnicos de Enfermagem:

1) 0 titular de diploma ou de certificado de Técnico de Enfermagem, expedido de acordo com a legislação e registrado pelo órgão competente;

2) 0 titular de diploma ou de certificado legalmente conferido por escola ou curso estrangeiro registrado em virtude de acordo de intercâmbio cultural ou revalidado no Brasil como diploma de Técnico de Enfermagem.

Art. 80. São Auxiliares de Enfermagem:

1) 0 titular de certificado de auxiliar de Enfermagem conferido por instituição de ensino, nos termos da Lei e registrado no órgão competente;

2) 0 titular de diploma a que se refere a Lei no 2.822, 14 de junho de 1956 ;

3) 0 titular do diploma ou certificado a que se refere o inciso III do art. $2^{\circ}$ da Lei $n^{0} 2.604$ de 17 de setembro de 1955 , expedido até a publicação da Lei n? 4.024, de 20 de dezembro de 1961;

4) 0 titular de certificado de Enfermeiro Prático ou Prático de Enfermagem, expedido até 1964 pelo Serviço Nacional de Fiscalização da Medicina e Farmácia, do Ministério de Saúde, ou por órgão congênere da Secretaria da Saúde das Unidades da Federação, nos termos do Decreto-Lei n. 23.774, de 22 de janeiro de 1934, do Decreto-Lei n? 8.778, de 22 de janeiro de 1946, e da Lei n? 3.640, de 10 de outubro de 1946;

5) 0 pessoal enquadrado como Auxiliar de Enfermagem, nos termos do Decreto-Lei n? 299, de 28 de fevereiro de 1967;

6) 0 titular do diploma ou certificado conferido por escola ou curso estrangeiro, segundo as leis do país, registrado em virtude de acordo de intercâmbio cultural ou revalidado no Brasil como certificado de Auxiliar de Enfermagem.

Art. 90. São Parteiras:

1) A titular do certificado previsto no art. $1 \%$ do Decreto-Lei no 8.778, de 22 de janeiro de 1946, observado o disposto na Lei n? 3.640 , de 10 de outubro de 1959 ;

2) A titular do diploma ou certificado de Parteira, ou 
equivalente, conferido por escola ou curso estrangeiro, segundo as leis do país registrado, em virtude de intercâmbio cultural ou revalidado no Brasil, até 2(dois) anos após a publicação desta Lei, como certificado de Parteira.

Art. 10: 0 desempenho das atividades de enfermaO gem constitui o objeto da profissão liberal de enfermeiro, ao qual é assegurada autonomia técnica no plane岁 jamento, organização, execução e avaliação dos serviĻos e da assistência de enfermagem.

Art. 11. 0 enfermeiro exerce todas as atividades de enfermagem, cabendo-lhe:

1) Privativamente:

a) direção do órgão de enfermagem integrante da estrutura básica da instituição de saúde, pública ou privada, e chefia de serviço e de unidade de enfermagem; b) organização e direção dos serviços de enfermagem e de suas atividades técnicas e auxiliares nas empresas prestadoras desses serviços;

c) planejamento, organização, coordenação, execução e avaliação dos serviços de assistência de enfermagem:

d) direção de escola, chefia de departamento e coordenação de cursos para formação de pessoal de enfermagem em todos os graus;

e) exercício do magistério nas disciplinas específicas de enfermagem no ensino de $2^{\circ}$ e $3^{\circ}$. graus, obedeciO das as disposições legais relativas ao ensino;

f) planejamento, programação e avaliação dos cursos

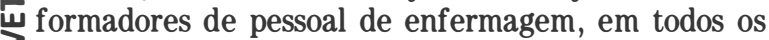
graus, atendidas as exigências legais;

g) composição de comissão julgadora para exames em disciplinas específicas de enfermagem, na seleção de pessoal, inclusive técnico e auxiliar, para cargo e emprego;

h) consultoria, auditoria e emissão de parecer sobre matéria de enfermagem;

i) consulta de enfermagem;

j) prescrição da assistência de enfermagem;

l) cuidados diretos de enfermagem a pacientes graves com risco de vida;

m) cuidados de enfermagem de maior complexidade técnica e que exijam conhecimentos de base científica e capacidade de tomar decisões imediatas;

2) Como integrante da equipe de saúde:

a) participação no planejamento, execução e avaliação da programação de saúde;

b) participação na elaboração; execução e avaliação dos planos assistenciais de saúde;

c) prescrição de medicamentos estabelecidos em programas de saúde pública e em rotina aprovada pela instituição de saúde; d) participação em projetos de construção ou reforma de unidades de internação;

e) prevenção e controle sistemático da infecção hospitalar e de doenças transmissíveis em geral;

f) prevenção e controle sistemático de danos que possam ser causados à clientela durante a assistência de enfermagem;

g) assitência de enfermagem à gestante, parturiente e puérpera;

h) acompanhamento da evolução e do trabalho de parto;

i) execução do parto sem distocia;

j) educação visando à melhoria de saúde da população;

Parágrafo único Às profissionais referidas no inciso II do art. $6^{\circ}$ desta Lei incumbe, ainda:

a) assistência à parturiente e ao parto normal;

b) identificação das distocias obstétricas e tomada de providências até a chegada do médico;

c) realização de episiotomia e episiorrafia e aplicação de anestesia local, quando necessária.

Art. 12\% 0 Técnico de Enfermagem exerce atividade de nível médio, envolvendo orientação e acompanhamento do trabalho de enfermagem em grau auxiliar, e participaçao no planejamento da assistência de enfermagem, cabendo-lhes especialmente:

a) participar da programação da assitência de enfermagem;

b) executar ações assistencial de enfermagem exceto as privativas do Enfermeiro, observado o disposto no parágrafo único do art. 11 desta Lei;

c) participar da orientação e supervisão do trabalho de enfermagem em grau auxiliar.

d) participar da equipe de saúde.

Art. 13\% O Auxiliar de Enfermagem exerce atividades de nível médio, de natureza repetitiva, envolvendo serviços auxiliares de enfermagem sob supervisão, bem como a participação em nível de execução simples, em processos de tratamento, cabendo-lhe especialmente:

a) observar, reconhecer e descrever sinais e sintomas;

b) executar ações de tratamento simples;

c) prestar cuidados de higiene e conforto ao paciente;

d) participar da equipe de saúde.

TArt. 14: 0 ensino de enfermagem de $1^{\circ}$ grau incluíse nas atribuições do enfermeiro e do técnico de enfermagem, obedecidas as exigências legais relativas ao > ensino.

Art. 15. As atividades referidas nos arts. 12 e 13 desta Lei, quando exercidas em instituições de saúde, públicas e privadas, e em programas de saúde, somente podem ser desempenhadas sob orientação e supervisão de Enfermeiro.

Ort. 16. O designativo "enfermeiro" é privativo de
serviços e atividades dirigidos ou exercidos por
"enfermeiro. 
Art. 179. 0 provimento de chefia de unidade de enfermagem em caso de comprovada carência de enfermeiros, obedecerá às normas baixadas pelo Conselho Federal de Enfermagem.

Art. 18. As entidades de direito privado que prestem 5 serviços de enfermagem ou exerçam atividades de for$>$ mação ou treinamento de recursos humanos de enfermagem serão registradas no Conselho Regional de Enfermagem, sem prejuízo de outros registros legalmente instituídos.

Parágrafo único. As entidades referidas neste artigo ficam sujeitas ao pagamento de anuidade. observado o disposto no art. 15 e seu XI da Lei no 5.905 de julho de 1973.

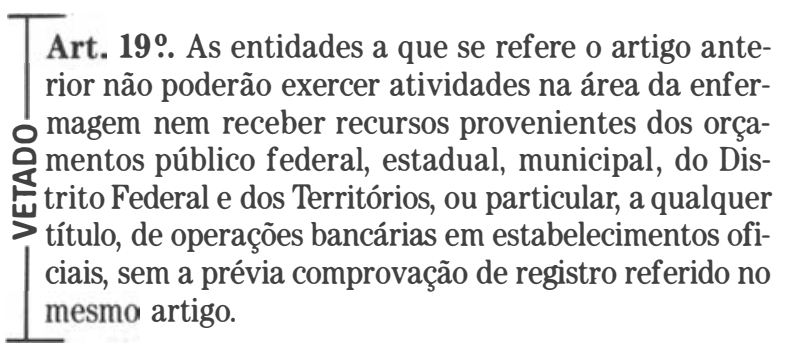

Art. 20\% Os órgãos de pessoal da administração pública direta e indireta, federal, estadual, municipal, do Distrito Federal e dos Territórios observarão, no provimento de cargos e funções e na contratação de pessoal de enfermagem, de todos os graus, os preceitos desta Lei.

Parágrafo único Os órgãos a que se refere este artigo promoverão as medidas necessárias à harmonização das situações já existentes com as disposições desta Lei, respeitados os direitos adquiridos quanto a vencimentos e salários.

Art. 21 ? Fica estendido aos profissionais de enfermagem e de suas atividades auxiliares o direito à prisão especial.

Art. 22\% O pessoal formado no subsistema do ensino O profissionalizante, conforme o disposto no $\S 4^{\circ}$. do art. Q $4^{0}$. e na alínea b do $\S 2^{\circ}$. do art. 50 da lei no 5.692 , de 11 de agosto de 1971, para atuação na área da enfermagem, será inscrito, em quadro próprio, no Conselho Regional de Enfermagem sob cuja jurisdição exercerá suas atividades, observadas as normas baixadas pelo Conselho Federal de Enfermagem.

Art. 23. O pessoal que se encontra executando tarefas de enfermagem, em virtude de carência de recursos humanos de nível médio nessa área, sem possuir formação específica regulada em lei, será autorizado pelo Conselho Federal de Enfermagem, a exercer atividades elementares de enfermagem, observado o disposto no art. 15 desta Lei.
Parágrafo único A autorização referida neste artigo, que obedecerá aos critérios baixados pelo Conselho Federal de Enfermagem, somente poderá ser concedida durante o prazo de 10 (dez) anos, a contar da promulgação desta Lei.

Art. 24: Transcorridos 10 (dez) anos da promulgação da presente lei, a instituição de saúde, pública ou privada, somente poderá admitir, nomear ou contratar, para execução de atividades de enfermagem pessoal de categoria profissional regulada em lei.

$\$$ Parágrafo único A restrição de que trata este artigo não se aplica aos agentes comunitários de saúde para efeito de sua integração aos programas de atenção primária de saúde, a cargo das repartições sanitárias competentes.

Art. 25. O Poder Executivo regulamentará esta Lei no prazo de 120 (cento e vinte) dias a contar da data de sua publicação.

Art. 26. Esta Lei entra em vigor na data de sua publicação.

Art. 27? Revogam-se as demais disposições em contrário.

Brasilia, em 25 de junho de 1986 , $165^{\circ}$ da Independência e 98․ da República. José Sarney Almir Pazzianotto Pinto

\section{ANEXO II \\ Texto do Decreto $n$ ? 94.406 (Regulamentação LEP)}

\section{Regulamenta a Lei no 7.498, de 25 de junho de 1986, que dispõe sobre o exercício da enfermagem, e dá outras providências.}

0 presidente da República usando das atribuições que lhe confere $o$ art. 81, item III, da Constituição, e tendo em vista o disposto no art. 25 da Lei no 7.498, de 25 de junho de 1986 .

\section{Decreta:}

Art. 19 0 exercício da atividade de enfermagem, observadas as disposições da Lei no 7.498 , de 25 de junho de 1986, e respeitados os graus de hatilitação, é privativo de Enfermeiro, Técnico de Enfermagem, Auxiliar de Enfermagem e Parteiro e só será permitido ao profissional inscrito no Conselho Regional de Enfermagem da respectiva região.

Art. 2\%. As instituições e serviços de saúde incluirão 
a atividade de enfermagem no seu planejamento e programação.

Art. 3: A prescrição da assistência de enfermagem é parte integrante do programa de enfermagem.

Art. 49 são Enfermeiros:

1) 0 titular do diploma de Enfermeiro conferido por instituição de ensino nos termos da lei;

2) 0 titular do diploma ou certificado de Obstetriz ou de Enfermeira Obstétrica, conferido nos termos da lei; 3) 0 titular do diploma ou certificado de Enfermeira e a titular do diploma ou certificado de Enfermaria Obstétrica ou de Obstetriz ou equivalente, conferido por escola estrangeira segundo as respectivas leis, registrado em virtude de acordo de intercãmbio cultural ou revalidado no Brasil como diploma de Enfermeiro, de Enfermeira Obstétrica ou de Obstetriz;

4) Aqueles que, não abrangidos pelos itens anteriores, obtiverem título de Enfermeiro conforme o disposto na letra d do Art. 30 do Decreto no 50.387, de 28 de março de 1961.

Art. 50. São Técnicos de Enfermagem:

1) 0 titular do diploma ou do certificado de Técnico de Enfermagem, expedido de acordo com a legislação e registrado no órgão competente;

2) 0 titular do diploma ou do certificado legalmente conferido por escola ou curso estrangeiro, registrado em virtude de acordo de intercâmbio cultural ou revalidado no Brasil como diploma de Técnico de Enfermagem.

Art. 69 São Auxiliares de Enfermagem:

1) $O$ titular de certificado de Auxiliar de Enfermagem conferido por instituição de ensino, nos termos da lei, e registrado no órgão competente;

2) 0 titular de diploma a que se refere a Lei no 2.822, de 14 de junho de 1986 :

3) 0 titular do diploma ou certificado a que se refere o item III do art. $2^{\circ}$. da Lei no 2.604, de 17 de setembro de 1955, expedido até a publicação da Lei no 4.024, de 20 de dezembro de 1961;

4) 0 titular do certificado de Enfermeiro Prático ou Prático de Enfermagem, expedido até 1964 pelo Serviço Nacional de Fiscalização da Medicina e Farmácia, do Ministério da Saúde, ou por órgão congênere da Secretaria de Saúde nas unidades da Federação, nos termos do Decreto n? 23.774, de 22 de janeiro de 1934, do Decreto-Lei n? 3.604, de 10 de outubro de 1959; 5) 0 pessoal enquadrado como Auxiliar de Enfermagem, nos termos do Decreto-lei n? 299, de 28 de fevereiro de 1967;

6) 0 titular do diploma ou certificado conferido por escola ou curso estrangeiro, segundo as leis do país, registrado em virtude de acordo de intercâmbio cultural ou reavalidado no Brasil como certificado de Auxiliar de Enfermagem.

Art. 79. São Parteiros:

1) 0 titular de certificado previsto no art. $1^{0}$ do Decreto-lei no 8.778, de 22 de janeiro de 1946, obser- vando o disposto na Lei $\mathrm{n}$ ? 3.640, de 10 de outubro de 1959 ;

2) 0 titular do diploma ou certificado de Parteiro, ou equivalente, conferido por escola ou curso estrangeiro, segundo as respectivas leis, registrado em virtude de intercâmbio cultural ou revalidado no Brasil até 26 de junho de 1988, como certificado de Parteiro.

Art. 89. Ao Enfermeiro incumbe:

1) Privativamente:

a) direção do órgão de enfermagem integrante da estrutura básica da instituição de saúde, pública ou privada, e chefia do serviço e de unidade de enfermagem; b) organização e direção dos serviços de enfermagem e de suas atividades técnicas e auxiliares nas empresas prestadoras desses serviços;

c) planejamento, organização, coordenação, execução e avaliação dos serviços da assistência de enfermagem; d) consultoria, auditoria e emissão de parecer sobre a matéria de enfermagem;

e) consulta de enfermagem;

f) prescrição da assistência de enfermagem;

g) cuidados diretos de enfermagem a pacientes graves com risco de vida;

h) cuidados de enfermagem de maior complexidade técnica e que exigem conhecimentos científicos adequados e capacidade de tomar decisões imediatas;

2) Como integrante da equipe de saúde:

a) participação no planejamento, execução e avaliação da programação da saúde;

b) participação na elaboração, execução e avaliação dos planos assistenciais de saúde;

c) prescrição de medicamentos previamente estabelecidos em programas de saúde pública e em rotinas aprovada pela instituição de saúde;

d) participação em projetos de construção ou reforma de unidades de internação;

e) prevenção e controle sistemático da infecção hospitalar, inclusive como membro das respectivas comissões;

f) participação na elaboração de medidas de prevenção e controle sistemático de danos que possam ser causados aos pacientes durante a assistência de enfermagem;

g) participação na prevenção e controle das doenças transmissíveis em geral e nos programas de vigilância epidemiológica;

h) prestação de assistência de enfermagem a gestante, parturiente, puérpera e ao recém nascido.

i) participaçp̃ao nos programas e nas atividades de assistência integral à saúde individual e de grupos específicos, particularmente daqueles prioritários e de alto risco;

j) acompanhamento da evolução e do trabalho de parto;

l) execução e assistência obstétrica em situação de emergência e execução do parto sem distocia; m) participação em programas e atividades de educa- 
ção sanitária, visando à melhoria de saúde do indivíduo, da família e da população em geral;

n) participação nos programas de treinamento e aprimoramento de pessoal de saúde, particularmente nos programas de educação continuada;

o) participação nos programas de higiene e segurança do trabalho e de prevenção de acidentes e de doenças profissionais e do trabalho;

p) participação na elaboração e na operacionalização do sistema de referência e contrareferência do paciente nos diferentes níveis de atenção à saúde;

q) participação no desenvolvimento de tecnologia apropriada à assistência de saúde;

r) participação em bancas examinadoras, em matérias específicas de enfermagem, nos concursos para provimento de cargo ou contratação de Enfermeiro ou pessoal técnico ou Auxiliar de Enfermagem.

Art. 99 Às profissionais titulares de diploma ou certificados de Obstetriz ou de Enfermeira Obstétrica, além das atividades de que trata 0 artigo precedente, incumbe:

1) Prestação de assistência à parturiente e ao parto normal;

2) Identificação das distocias obstétricas e tomada de providências até a chegada do médico;

3) Realização de episitomia e episiorrafia com aplicação de anestesia local, quando necessária.

Art. 10\% O Técnico de Enfermagem exerce as atividades auxiliares, de nível médio técnico, atribuídas à equipe de enfermagem, cabendo-lhe:

1) Assistir ao Enfermeiro:

a) no planejamento, programação, orientação e supervisão das atividades de assistência de enfermagem;

b) na prestação de cuidados diretos de enfermagem a pacientes em estado grave;

c) na prevenção e controle das doenças transmissíveis e em geral em programas de vigilância epidemiológica; d) na prevenção e no controle sistemático da infecção hospitalar;

e) na prevenção e controle sistemático de danos físicos que possam ser causados a pacientes durante a assistência de saúde;

f) na execução dos programas referidos nas letras I e o do item II do art. 8.

2) executar atividades de assistência de enfermagem, excetuadas as privativas do enfermeiro e as referidas no art. $9^{\circ}$ deste Decreto;

3) Integrar a equipe de saúde.

Art. 11 \% O Auxiliar de Enfermagem executa as atividades auxiliares, de nível médio, atribuidas à equipe de enfermagem, cabendo-lhe:

1) Preparar o paciente para consultas, exames e tratamentos;

2) Observar, reconhecer e descrever sinais e sintomas, ao nível de sua qualificação;

3) Executar tratamentos especificamente prescritos, ou de rotina, além de outras atividades de enfermagem, tais como:

a) ministrar medicamentos por via oral e parenteral;

b) realizar controle hídrico;

c) fazer curativos;

d) aplicar oxigenioterapia, nebulização, enteroclisma, energia e calor ou frio;

e) executar tarefas referentes a conservação e aplicação de vacinas;

f) efetuar o controle de pacientes e de comunicantes em doenças transmissíveis;

g) realizar testes e proceder à sua leitura, para subsídio de diagnóstico;

h) colher material para exames laboratoriais;

i) prestar cuidados de enfermagem pré e pós-operatórios;

j) circular em sala de cirurgia e, se necessário, instrumentar;

l) executar atividades de desinfecção e esterilização;

4) Prestar cuidados de higiene e conforto ao paciente e zelar por sua segurança, inclusive:

a) alimentá-lo ou auxiliá-lo a alimentar-se;

b) zelar pela limpeza e ordem do material de equipamentos e de dependências de unidades de saúde;

5) Integrar a equipe de saúde;

6) Participar de atividades de educação em saúde, inclusive:

a) orientar os pacientes na pós-consulta, quanto ao cumprimento das prescrições de enfermagem e médicas;

b) auxiliar o Enfermeiro e o Técnico de Enfermagem na execução dos programas de educação para a saúde;

7) Executar os trabalhos de rotina vinculados à alta de pacientes;

8) Participar dos procedimentos pós-morte.

Art. 12\% Ao parteiro incumbe:

1) Prestar cuidados à gestante e à parturiente;

2) Assistir ao parto normal, inclusive em domicílios e,

3) Cuidar da puérpera e do recém-nascido.

Parágrafo único As atividades de que trata este artigo são exercidas sob supervisão de Enfermeira Obstetra, quando realizadas em instituições de saúde e, sempre que possível, sob contrle e supervisão de unidade de saúde, quando realizadas em domicílio ou onde se fizerem necessárias.

Art. 13. As atividades relacionadas nos arts, 10 e 11 somente poderão ser exercidas sob supervisão, orientação e direção de Enfermeiro.

Art. 14. Incumbe a todo o pessoal de enfermagem:

1) Cumprir e fazer cumprir o Código de Deontologia da Enfermagem;

2) Quando for o caso, anotar no prontuário do paciente as atividades da assistência da enfermagem para fins estatísticos.

Art. 15? Na administração pública direta e indireta, federal, estadual, municipal, do Distrito Federal e dos Territórios, será exigida como condição essencial para 
provimento de cargos e funções e contratação de pessoal de enfermagem de todos os graus, a prova de inscrição no conselho Regional de Enfermagem da respectiva região.

Parágrafo único Os órgãos e entidades compreendidos neste artigo promoverão, em articulação com o Conselho Federal de Enfermagem, as medidas necessárias à adaptação das situações já existentes com as disposições deste Decreto, respeitados os direitos adquiridos quanto a vencimentos e salários.

Art. 16. Este Decreto entra em vigor na data de sua publicação.

Art. $1^{\circ}$. Revogam-se as disposições em contrário.

Brasilia, 08 de junho de 1987

$166^{\circ}$ da Independência e 99 da República. José Sarney

Eros Antonio de Almeida

\section{ANEXO III}

\section{Texto da Lei $n$ ? 2604 (LEP-55)}

\section{Regula o exercício da enfermagem profissional}

Art. 19. É livre o exercício de enfermagem em todo o território nacional, observadas as disposições da presente lei.

Art. 29. Poderão exercer no país:

1) $\mathrm{Na}$ qualidade de enfermeiro:

a) os possuidores de diploma expedido no Brasil, por escolas oficiais ou reconhecidas pelo Governo Federal, nos termos da Lei n? 775, de 6 de aogsto de 1949;

b) os diplomados por escolas estrangeiras, reconhecidas pelas leis de seu pais e que revalidaram seus diplomas de acordo com a legislação em vigor;

c) os portadores de diplomas de enfermeiros, expedidos pelas escolas e cursos de enfermagem das forças armadas nacionais e forças militarizadas, que estejam habilitados mediante aprovação, naquelas disciplinas, do corrículo estabelecido na Lei n? 775, de 6 de agosto de 1949 , que requererem o registro de diploma na Diretoria do Ensino Superior do Ministério da Educação e Cultura.

2) $\mathrm{Na}$ qualidade de obstetriz:

a) os possuidores de diploma expedido no Brasil, por escolas de obstetrizes, oficiais ou reconhecidas pelo Governo Federal, nos termos da Lei no 775, de 6 de agosto de 1949 ;

b) os diplomados por escolas de obstetrizes estrangeiras, reconhecidas pelas leis do país de origem e que revalidaram seus diplomas de acordo com a legislação em vigor.

3) Na qualidade de auxiliar de enfermagem, os protadores de certificados de auxiliar de enfermagem, conferidos por escola oficial ou reconhecida nos termos da Lei $n$ ? 775, de 6 de agosto de 1949 e os diplomados pelas escolas e cursos de enfermagem das forças armadas nacionais e forças militarizadas que não se acham incluídos na letra "c" do item I do art. $2^{\circ}$. da presente lei.

4) Na qualidade de parteira, os portadores de certificado de parteira, conferido por escola oficial ou reconhecida pelo Governo Federal, nos termos da Lei n? 775 , de 6 de aogsto de 1949 .

5) Na qualidade de enfermeiros práticos ou práticos de enfermagem:

a) os enfermeiros práticos amparados pelo Decreto $n$ ? 23.774, de 11 de janeiro de 1934;

b) as religiosas de comunidade amparadas pelo Decreto n? 22.257 , de 26 de dezembro de 1932 ;

c) os portadores de certidão de inscrição, conferida após o exame de que trata o Decreto no 8.778, de 22 de janeiro de 1946.

6) $\mathrm{Na}$ qualidade de parteiras práticas, os portadores de certidão conferida após o exame de que trata o Decreto n? 8.778, de 22 de janeiro de 1946 .

Art. 3\% São atribuições dos enfermeiros, além do exercício de enfermagem:

a) direção dos serviços de enfermagem nos estabelecimentos hospitalares e de saúde pública, de acordo com o art. 21 da Lei no 775, de 6 de agosto de 1949; b) participação do ensino em escolas de enfermagem e de auxiliar de enfermagem;

c) direção de escolas de enfermagem e de auxiliar de enfermagem;

d) participação nas bancas examinadoras de práticos de enfermagem.

Art. 4. São atribuições das obstetrizes, além do exercício da enfermagem obstétrica:

a) direção dos serviços de enfermagem obstétrica nos estabelecimentos hospitalares e de Saúde Pública especializados para a assistência obstétrica;

b) participação no ensino em escolas de enfermagem obstétrica ou em escolas de parteiras;

c) direção de escolas de parteiras;

d) participação nas bancas examinadoras de parteiras práticas.

Art. 50. São atribuições dos auxiliares de enfermagem, enfermeiros práticos e práticos de enfermagem, todas as atividades da profissão, excluídas as constantes nos ítens do art. 30, sempre sob orientação médica ou de enfermeiro.

Art. 6? São atribuições das parteiras as demais atividades da enfermagem obstétrica não constantes dos itens do art. $4 \%$.

Art. 7? Só poderão exercer a enfermagem, em qualquer parte do território nacional, os profissionais cujos títulos tenham sido registrados ou inscritos no Departamento Nacional de Saúde ou na repartição sanitária correspondente nos Estados e Territórios.

Art. 89 O Ministério do Trabalho, Indústria e Comércio só expedirá carteira profissional aos portadores de 
diplomas, registros ou títulos de profissionais de enfermagem mediante a apresentação do registro dos mesmos no Departamento Nacional de Saúde ou em repartição sanitária correspondente nos Estados e Territórios.

Art. 9: Ao Serviço Nacional de Fiscalização da Medicina, órgão integrante do Departamento Nacional de Saúde, cabe fiscalizar, em todo o território nacional, diretamente ou por intermédio das repartições sanitárias correspondentes nos Estados e Territórios, tudo que se relacione com o exercício da enfermagem.

Art. 10\% Vetado.

Art. 119. Dentro do prazo de 120 (cento e vinte) dias da publicação da presente lei, os hospitais, clínicas, sanatórios, casas de súde, departamentos de saúde e instituições congêneres deverão remeter ao Serviço Nacional de Fiscalização da Medicina a relação pormenorizada dos profissionais de enfermagem da qual cons- te idade, nacionalidade, preparo técnico, títulos de habilitação profissional, tempo de serviço de enfermagem e função que exercem.

Art. 12: Todos os profissionais de enfermagem são obrigados a notificar, anualmente, à autoridade respectiva sua residência e sede de serviço onde exercem atividade.

Art. 13\% 0 prazo da vigência do Decreto n? 8.778 , de 22 de janeiro de 1946, é fixado em 1(um) ano, a partir da publicação da presente Lei.

Art. 14. Ficam expressamente revogados os Decretos n. 23.774, de 22 de janeiro de 1934, 22.257, de 26 de dezembro de 1932, e 20.109, de 15 de junho de 1931 .

Art. 15. Dentro de 120 (cento e vinte) dias da publicação da presente Lei, o Poder Executivo baixará o respectivo regulamento.

Art. 16 ${ }^{\circ}$ Esta Lei entrará em vigor na data de sua publicação, revogadas as disposições em contrário. 